\title{
MENYINGKAP JIWA DAN RASA KEADILAN HUKUM BANGSA INDONESIA DALAM NASKAH KLASIK BERAKSARA LAMPUNG (UNDANG-UNDANG KUNTARA RAJANITI DAN JUGULMUDA)
}

\author{
Bunyana Sholihin \\ Dosen Fakultas Syariah UIN Raden Intan Lampung \\ J1 Endro Suratmin Sukarame Bandar Lampung \\ email: bunyanasholihin@radenintan.ac.id
}

\begin{abstract}
Abstark: Penelitian ini menyingkap jiwa dan rasa keadilan hukum bangsa Indonesia dalam naskah perundang-undangan klasik Lampung Kuntara Rajaniti Dan Jugulmuda. Berlandaskan teori sosiologi hukum, bahwa suatu hukum akan berjalan tegak di tengah suatu masyarakat apabila hukum yang berlaku sesuai dengan jiwa dan rasa keadilan hukum masyarakat yang bersangkutan. Maka yang menjadi permasalahan dalam kajian ini adalah: 1. Apa hakekat jiwa dan semangat keadilan hukum bangsa Indonesia? 2. Adakah nilai jiwa dan semangat keadilan hukum bangsa Indonesia dalam Naskah Perundang-Undang Klasik Kuntara Rajaniti dan Jugulmuda?

Melalui penelitian ini ditemukan bahwa naskah yang diteliti memuat tata aturan pidana dan perdata dan sempat lama berlaku di nusantara sebelum diberlakukannya prundang-undangan kolonial Belanda. Dari sini dapat disimpulkan bahwa Naskah Perundang-Undangan Klasik Lampung Kuntara Rajaniti dan Jugulmuda sesuai dengan jiwa dan rasa keadilan hukum bangsa Indonesia.

Selanjutnya disarankan agar pemerintah Negara Kesatuan Republik Indonesia melestarikan dan mengakomodir nilai jiwa hukum dan rasa kedilan bangsa yang termuat dalam Naskah Perundang-Undangan Klasik Kuntara Rajaniti dan Jugulmuda.
\end{abstract}

Kata Kunci: Kuntara Rajaniti - Perundang-Undangan Klasik Lampung

\section{A. Pendahuluan}

Aturan hukum pidana yang berlaku di Indonesia hingga saat ini masih merupakan aturan hukum pidana peninggalan kolonial Belanda yang secara substansi hukum adalah aturan hukum penjajah untuk bangsa yang terjajah, karena aturan hukum pidana yang berlaku di Indonesia hingga saat ini merupakan adopsi dari aturan pidana peninggalan kolonial Belanda dalam bentuk perundang-undangan pidana hasil terjemahan dari aturan hukum pidana yang termuat dalam kitab "Wetboek van Strafrecht voor Nederlandsch Indie 1915". Berdasarkan firman raja Belanda (Invoeringsverordening) tanggal 4 Mei 1917 (Stb. 1917 nomor 497) aturan pidana dimaksud secara khusus telah diberlakukan oleh pemerintahan kolonial Belanda terhadap bangsa jajahannya di nusantara yaitu terhitung mulai tanggal 01 Januari 1918. Sedangkan aturan pidana yang diberlakukan oleh pemerintahan 
Belanda untuk bangsanya sendiri adalah aturan pidana yang disusun untuk bangsa Belanda yang merdeka termuat dalam kitab "Wetboek van Strafrecht 1881".'

Mengingat suatu teori sosiologi hukum bahwa suatu aturan hukum akan dapat berjalan tegak, diterima dan dianut serta dijunjung oleh suatu masyarakat apabila hukum yang berlaku sesuai dengan jiwa hukum dan rasa keadilan masyarakat yang bersangkutan. $^{2}$ Agar suatu aturan pidana yang diberlakukan di Indonesia lebih efektif dapat mewujudkan visi dan tujuan hukum itu sendiri maka idealnya hukum pidana yang berlaku di Indonesia adalah bukum yang sesuai dengan jiwa bukum dan semangat keadilan bangsa Indonesia.

Sebagai realita sekarang bangsa Indonesia adalah bangsa yang merdeka, berjiwa hukum dan semangat keadilan hukum tertentu. Secara fakta, sebelum diberlakukan perundang-undangan kolonial Belanda bangsa Indonesia telah mempunyai perundang-undangan sendiri, di-antranya PerundangUndangan Kuntara Rajaniti dan Jugulmuda yang pernah berlaku secara luas di sebagian wilayah nusantara.

Dari itu semua maka yang menjadi permasalahan dalam pnelitian ini adalah:

1. Apa hakekat jiwa dan semangat keadilan hukum bagi bangsa Indonesia?

2. Adakah cerminan jiwa dan semangat keadilan hukum bangsa Indonesia dalam Naskah Undang-Undang Klasik Kuntara Rajaniti dan Jugulmuda?

1 Wirjono Prodjodokoro, Azas-Azas Hukum Pidana Di Indonesia, P.T. Eresco, Bandung, 1979., hal. 5-7.

2 Sucipto Raharjo, Ilmu Hukum, Pen. Alumni, Bandung 1982., hal. 176.
Untuk menjawab permasalahan berikut perlu diadakan kajian khusus mengenai jiwa bukum dan semangat keadilan bangsa Indonesia dalam Naskah Undang-Undang Klasik Kuntara Rajaniti dan Jugulmuda. Adapun tujuan yang hendak dicapai dari penelitian ini adalah:

1. Untuk mengetahui bentuk dan sifat jiwa hukum dan semangat kedilan bangsa Indonesia.

2. Untuk mengetahui dan menyingkap keberadaan jiwa hukum dan semangat keadilan bangsa Indonesia dalam Naskah Undang-Undangan Klasik Kuntara Rajaniti dan Jugulmuda. Adapun kegunaan serta manfaat yang dari penelitian ini adalah:

1. Mengenal mengingat kembali nilainilai kebijakan hukum leluhur bangsa

2. Memberikan kontribusi ilmiah bagi pengembangan kepustakaan nusantara.

Sejauh ini belum pernah ada ditemukan satu penelitianpun yang mengangkat tema khusus mengenai jiwa dan semangat keadilan hukum leluhur bangsa Indonesia yang termuat dalam naskah Undang-undangan klasik Kuntara Rajaniti dan Jugul Muda. Dengan demikian penelitian ini merupakan penelitian pertama mengenai keberadaan jiwa hukum dan semangat keadilan bangsa Indonesia yang tercakup dalam naskah perundaangundangan klasik.

Sebelum perundang-undangan pemerintah Belanda diberlakukan di Indonesia, hakekatnya bangsa Indonesia telah memiliki undangundang yang secara lengkap mengatur tata kehidupan dan prilaku kehidupan bermasyarakat.

Naskab Kuntara Rajaniti Dan Jugulmuda sebenarnya bukan hanya sekedar memuat masalah tata cara adat 
secara seremonial, seperti upacara pernikahan, kematian dll., tapi kitab tersebut memuat peraturan-peraturan kemasyarakatan atau yang lebih tepat disebut perundang-undangan. Sebagaimana disebutkan dalam manuskrip tersebut, bahwa naskah Kuntara Raja Niti dan Jugul Muda adalah naskah perundang-undangan yang berlaku di tiga wilayah kerajaan besar di nusantara, yaitu Majapahit, Pajajaran, dan Lampung. ${ }^{3} \quad$ Sebagai naskah perundang-undangan atau dasar hukum kehidupan bermasyarakat, naskah tersebut ditulis dengan sistematis. Setiap pembahasan diatur dalam babbab.

Naskah perundang-undangan klasik Kuntara Rajaniti dan Jugul Muda ini seandainya pemerintah kolonial Belanda tidak memaksakan berlakunya Wetboek van Strafrecht voor Nederlandsch Indie 1915 (Kitab Undang-Undang Pidana untuk. Bangsa Jajahan Di Wilayah Jajahan 1915), diduga kuat naskah perundangundangan klasik Kuntara Rajaniti dan Jugul Muda niscaya masih berlaku sampai sekarang. Karena naskah Kuntara Rajaniti dan Jugul Muda dimaksud sudah lengkap memuat materi hukum pidana dan materi hukum perdata secara komprehensif dan sistimatis dalam urutan $\mathrm{Bab}$ dan pasal.

Kitab tersebut secara terperinci mengatur tata cara hidup bermasyarakat dan bernegara yang termuat dalam pasal-pasal. Dalam pasal-pasal juga diatur tata cara berperahu dan cara menggunakan air, bahkan sampai tentang cara seorang laki-laki bertamu ke rumah perempuan ketika suaminya tidak ada di rumah. Tiap-tiap pasal tidak hanya memuat

3 Naskah Kuntara Rajaniti Dan Jugulmuda, h. 108-109 perintah dan larangan, tapi juga mencakup sanksi hukuman bagi yang melanggar peraturan tersebut. Demikian lengkapnya cakupan materi hukum yang termuat dalam Kuntara Rajaniti Dan Jugulmuda yang telah sempat berlaku di sebagian wilayah nusantara dalam rentang waktu yang cukup lama.

Memperhatikan isi dan cakupannya, Naskah Kuntar Rajaniti Dan Jugul Muda dipastikan sebagai hasil rumusan suatu Tim Ahli Hukum yang sengaja dibentuk oleh penguasa untuk diberlakukan pada masyarakat selaku subjek dan objek hukum pada zamannya. Dengan demikian rumusan hukum yang dihasilkan dapat diterima oleh semua kalangan karena sesuai dengan jiwa hukum dan semangat keadilan masyarakatnya.

Sehubungan dengan itu semua, maka naskah yang ditetapkan untuk diteliti dan dikaji adalah naskah Undangundangan Kuntara Rajaniti dan Jugulmuda yang tertuang dalam aksara Lampung kuno yang masih tersimpan pada pribadi tokoh Lampung di Kalianda Lampung Selatan. Dalam upaya mencarikan jawaban atas permasalahan penelitian yang akan ditempuh adalah penelitian kepustakaan yang didukung dengan data lapangan.

Kajian tentang Hukum Pidana dalam kaitannya dengan Supremasi hukum di Indonesia tidak lepas dari uraian mengenai seluk-beluk Hukum Pidana yang berlaku atau pernah berlaku dan mungkin berlaku sebagai acuan bertidak dan berbuat bagi bangsa Indonesia, baik secara substansi material hukum (material low) maupun budaya hukumnya (cultural low). Oleh karena itu penelitian yang direncanakan di sini adalah penelitian kepustakaan (library research). Sifat penelitian ini adalah Penelitian Normatif yang akan 
mengurai nilai-nilai hukum yang sesuai dengan jiwa dan semangat keadilan hukum bangsa Indonesia sehingga menjamin tegaknya supremasi hukum di Indonesia, dengan merujuk kepada sumber primer Naskah PerundangUndangan Klasik Lampung Kuntara Rajaniti dan Jugulmuda dan sumbersumber kepustakaan dan dokumen lainnya.

1. Pendekatan Penelitian

Penelitian ini bersifat filologi yang akan mengadakan telaah secara cermat dan mendalam mengenai kandungan nilai jiwa hukum dan semangat keadilan bangsa Indonesia dalam Naskah Klasik Beraksara Lampung Perundang-Undangan Kuntara Rajaniti dan Jugul Muda dengan menggunakan pendekatan sejarah.

2. Subjek Penelitian

Adapun penelitian ini dilakukan oleh lembaga institusi Perguruan Tinggi yaitu Lembaga Penelitian (Puslit) UIN Raden Intan Lampung yang dilakukan oleh seorang dosen senior, yaitu Dr. Bunyana Sholibin M. $A g$ sebagai penelitian konpetitif individual. Hal ini sebagai realisasi dari salah-satu kegiatan Lembaga Penelitian UIN Raden Intan Tahun 2018.

3. Jenis data

Data yang dibutuhkan dan dicari melalui penelitian ini adalah data skunder yaitu data yang tersimpan dalam dokumen kepustakaan ataupun naskah yang dimiliki dan disimpan oleh pribadi-pribadi masyarakat serta informasi dan keterangn dari para tokoh dan pakar adat dan budaya Lampung. Adapun sumber data dalam penelitian ini adalah kepustaaan pribadi para tokoh masyarakat adat Lampung dan Musium Lampung Sangbumi Khuwa Jukhai.

4. Teknik pengumpulan data

Data yang akan dihimpun melalui penelitian ini adalah data tentang nilai-nilai jiwa bukum dan semangat keadilan lelubur bangsa Indonesia dalam Naskah Undang-Undang Klasik Kuntara Rajaniti dan Jugul Muda yang diharapkan dapat menjamin tegaknya suprimasi hukum di Indonesia.

Dalam upaya pengumpulan data dimaksud akan ditempuh melalui teknik telaah teks. Di samping itu akan dilengkapi dengan menggunakan teknik observasi partisipasi.

5. Teknik analisa Naskah

Naskah yang dipilih sebagai objek penelitian yaitu naskah Undangundang Kuntara Rajaniti dan Jugul Muda akan dianalisis dengan menggunakan teknik Diskriptif Analitis.

\section{B. Pembahasan}

1. Jiwa Dan Rasa Keadilan Hukum Bangsa Indonesia

Di sini perlu diuraikan terlebih dahulu pengertian bangsa Indonesia. Menurut Petrus Citra Triwamwoto dikemukakan bahwa bangsa adalah suatu kelompok manusia yang secara nasional memiliki identitas bersama, dan mempunyai kesamaan bahasa, ideologi, budaya, sejarah, dan tujuan yang sama. ${ }^{4}$ Lain lagi definisi yang dikemukakan oleh B.Herry-Priyono dinyatakan bahwa bangsa adalah sekelompok manusia yang berada dalam suatu ikatan batin yang dipersatukan karena memiliki persamaan sejarah, serta cita-cita yang

\footnotetext{
4 Petrus Citra Triwamwoto. Kewarganegaraan. Grasindo, Jakarta, 2004, h. 118.
} 
sama. ${ }^{5} \quad$ Dari dua pengertian bangsa tesebut dapat disatukan bahwa bangsa itu adalah kesatuan kelompok manusia yang diikat oleh kesamaan ideologi, budaya, wilayah, sejarah dan cita-cita.

Sedangkan Indonesia, adalah negara di Asia Tenggara yang dilintasi garis khatulistiwa dan berada di antara daratan benua Asia dan Australia, serta antara Samudra Pasifik dan Samudra Hindia.

Dari gabungan pengertian dua istilah bangsa dan Indonesia itulah Zulyani Hidayah memberikan pengertian bahwa Bangsa Indonesia sebagai wujud kesatuan bangsa yang terdiri dari berbagai suku bangsa yang menghuni wilayah nusantara mulai dari Aceh hingga Meroke melebur menjadi satu kesatuan bangsa. ${ }^{6}$

Namun terkait dengan gabungan 2 pengertian bangsa yang lebih mencakup maka pengertian bangsa Indonesia dapat dikembangkan sehingga lebih mengikat, yaitu wujud kesatuan bangsa dari berbagai suku bangsa yang menghuni wilayah nusantara mulai dari Sabang hingga Meroke diikat oleh kesamaan ideologi, budaya, wilayah, sejarah dan cita-cita melebur menjadi satu kesatuan bangsa.

Jelasnya bangsa Indonesia terbentuk di atas kesamaan ideologi, budaya, wilayah, sejarah dan cita-cita. Secara ediologi, seluruh etnis bangsa Indonesia adalah bangsa yang beragama. Tidak satupun etnis suku bangsa Indonesia tertentu yang tidak beragama. Semua etnis dan kelompok bangsa adalah etnis yang beragama. Ada yang beragama Islam, ada pula yang beragama Hindu,

${ }^{5}$ B.Herry-Priyono, Guru-Guru keluburan, PT Kompas Media Nusantar, Jakarta, .2010, h. 67.

6 Zulyani Hidayah, Ensiklopedi Suku Bangsa di Indonesia, Yayasan Pustaka Obor Indonesia, Jakarta, 2015, h. xiii.
Budha, Nasrani, animisme atau dinamisme. Pada intinya seluruh etnis dan kelompok bangsa Indonesia adalah etnis bangsa yang berketuhanan. Dengan kesamaan idiologi berketuhanan itulah mereka merasa satu dan menjadikan Ketubanan Yang Maha Esa sebagai landasan dasar yang pertama dan utama dalam kehidupan berbangsa.

Secara budaya, seluruh etnis suku bangsa yang hidup di kepulauan nusantara mengalami tahapan peroses budaya secara bersama. Masing-masing etnis suku bangsa yang ada memang sudah mulai mengukir peradabannya sebagai manusia yang berperadadaban nusantara. Merka hidup melintasi perkembangan sejarah peradaban manusia, mulai dari priode prasejarah, priode Megalitikum - masa batu (Paleolitikum - masa batu kasar, dan Neolitikum - batu halus) serta masa Perunggu dan Besi sampai awal priode modern, mereka hidup bahagia sebagai manusia yang berperadaban nusantara dengan segala kesuburan, keindahan dan kekayaan alamnya. Mereka hidup aman, bahagia dan sejahtera dengan tata kehidupan kelompok manusia yang adil dan beradab, bebas mengadakan hubungan kerjasama antar etnis suku dan bangsa. Namun memasuki pertengahan periode modern mereka kehilangan kebahagiaan, keamanan, kesejahteraannya dengan datangnya bangsa penjajah yang merampas kekayaan dan kebesan hidup mereka di seluruh kawasan nusantara dari Sabang sampai Maoroke. Hak kemanusiaan mereka hilang dirampas dan dikuasai oleh bangsa penjajah. Mereka hidup tak lebih dari sebagai anjing penjaga dan pengaman kekakayaan dan kekuasaan penjajah. Oleh karena itu dari kesamaan perjalanan sejarah budaya, mereka merasa sama senasib 
sepenanggungan,

sama-sama

mendambakan kehidupan yang

berprikemanusiaan yang adil dan beradab. Akhirnya merekapun sepakat menjadikan Kemanusiaan yang adil dan beradab sebagai dasar kehidupan manusia.

Secara wilayah, seluruh etnis bangsa Indonesia tinggal di wilayah yang sama yaitu hamparan kepulauan nusantara dalam cuaca dan suhu alam yang sama. Dengan kesamaannya mereka merasa satu, selanjutnya mereka menjadikan Persatuan Indonesia sebagai landasan dasar kehidupan berbangsa dan bernegara.

Secara sejarah, seluruh etnis dan kelompok bangsa Indonesia mempunyai sejarah yang sama. Yaitu sebagai bangsa yang terjajah dalam rentang masa berabad-abad. Mereka mengalami sejarah penderitaan yang sama, selalu bersama menghadapi musuh yang sama, yaitu penjajah. Dengan kesamaannya mereka merasa satu, senasib seperjuangan. Sehingga mereka menjadikan Kerakyatan yang dipimpin oleh hikmah kebijaksanaan dalam permusyawaratan dan perwakilan sebagai landasan dasar dalam kehidupan berbangsa dan bernegara.

Dari kesamaan ideologi, budaya, wilayah, sejarahnya itulah sehingga akhirnya mereka mendambakan suasana kehidupan yang sama, yaitu hidup merdeka bersama untuk mewujudkan kehidupan yang adil dan makmur secara merata antar sesama. Sehingga mereka sepakat menetapkan Keadilan sosial bagi selurub rakyat Indonesia sebagai landasan kehidupan pribadi dan kelompok serta kehidupan berbangsa dan bernegara.

Dari lima butir kesamaan nilai berbangsa itu mereka sepakati bersama sebagai landasan prilaku kehidupan bersama bagi bangsa yang hidup di kepulauan nusantara sejak sebelum terbentuknya negara Indonesia yang merdeka dengan kesepakatan sebutan Pancasila. Pancasila berarti lima landasan yang menjadi pijakan dan citacita bersama dalam kehidupan bangsa. Adapun kelima sila dari Pancasila dimaksud adalah sbb:

a. Ketuhanan Yang Maha Esa

b. Kemanusiaan yang adil dan beradab

c. Persatuan Indonesia

d. Kerakyatan yang dipimpin oleh hikmah kebijaksanaa dalam permusyawaratan dan perwakilan

e. Keadilan sosial bagi seluruh rakyat Indonesia.

2. Pancasila sebagai Pandangan Hidup, Jiwa dan Kepribadian Bangsa Indonesia

Demikian bangsa Indonesia, memiliki dan meyakini bersama kebenaran nilainilai Pancasila, sehingga Pancasila menjelma menjadi pandangan hidupnya. Keyakinan tersebut menjadi kekuatan bangsa Indonesia untuk berjuang dan membangun demi mencapai cita-cita bangsa. Pancasila disebut juga sebagai jiwa bangsa. Karena Pancasila telah mendorong bangsa Indonesia untuk menata dan mengatur hidupnya sesuai dengan yang terkandung di dalam pandangan hidupnya.

Tatanan kehidupan bangsa yang secara menyeluruh terpola dalam nilainilai bangsa disebut kepribadian bangsa. Kepribadian bangsa mempunyai corak yang khas, merupakan ciri yang membedakan bangsa itu dengan bangsa-bangsa lain. Ini berarti, kepribadian bangsa juga merupakan ciri khas atau jati-diri suatu bangsa. Jati-diri suatu bangsa yang membentuk identtas sistem kenegaraan dan sistem 
hukum suatu bangsa itulah jiwa hukum bangsa yang bersangkutan. ${ }^{7}$

a. Analisis Fisik Naskah

Naskah Kuntara Rajaniti Dan Jugulmuda adalah naskah PerundangUndangan klasik yang memuat materi aturan pidana, perdata dan lalu-lintas angkutan barang lengkap dengan aturan acaranya masing-masing. Naskah ini didapatkan dari koleksi tokoh masyarakat, H. Hasan Basri, salah-satu keturunan Raden Intan yang berdomisili di desa Kahuripan Kalianda Lampung Selatan.

Naskah ini seutuhnya bertuliskan aksara Lampung kuno, namun bunyi naskah seutuhnya berbahasa Jawa dialog Banten kuno. Naskah ini adalah naskah kuno yang sudah berusia ratusan tahun. Dalam naskah ini tertulis angka tanggal 3 bulan Muharam tahun 1243) ${ }^{8}$ sebagai peringatan tatkala Minake Ratu naik takhta menjadi Raja Mangku Dalom Kusuma Khatu sekaligus mendirikan shalat Jum at pertama dalam sejarah kerajaan maritim.

\section{b. Analisis Isi Naskah}

Sebelum perundang-undang pemerintah Belanda diberlakukan di Indonesia, bangsa Indonesia telah memiliki undang-undang yang secara lengkap mengatur tata kehidupan dan prilaku kehidupan bermasyarakat.

Naskah klasik Kuntara Rajaniti dan Jugulmuda adalah satu naskah perundang-undangan yang pernah berlaku di sebagian wilayah nusantara dalam rentang waktu yang cukup lama. Naskah tersebut memuat berbagai aturan kehidupan bermasyarakat yaitu aturan mengenai pidana, perdata,

7 Carl von Savigny, Von Beruf Unserer Zeit fur Gesetzgebung und Rechtswissenschaft, Mohr und Zimmer, Heidelberg, 1814., h.

${ }^{8}$ Op.Cit., Naskah Kuntara Rajaniti Dan Jugulmuda, h. 177-178. angkutan lalu-lintas, masing-masing lengkap dengan hukum acaranya. Dalam pasal-pasal juga diatur tata cara berperahu dan cara menggunakan air, bahkan sampai tentang cara seorang laki-laki bertamu ke rumah perempuan ketika suaminya tidak ada di rumah. Tiap-tiap aturan tidak hanya memuat peraturan, tetapi juga lengkap dengan ancaman hukuman bagi yang melanggar peraturan tersebut.

Demikian lengkapnya cakupan materi hukum yang termuat dalam Kuntara Rajaniti Dan Jugul Muda. Memperhatikan isi dan cakupannya, Naskah Kuntar Rajaniti Dan Jugul Muda dipastikan sebagai hasil rumusan suatu Tim Ahli Hukum yang sengaja dibentuk oleh penguasa untuk diberlakukan pada masyarakat selaku subjek dan objek hukum pada zamannya. Dengan demikian rumusan hukum yang dihasilkan dapat diterima oleh semua kalangan karena sesuai dengan jiwa hukum dan semangat keadilan masyarakatnya.

Naskab Kuntara Rajaniti dan Jugulmuda sebenarnya bukan hanya sekedar memuat masalah tata cara adat secara seremonial, seperti upacara pernikahan, kematian dll., tapi kitab tersebut memuat peraturan-peraturan kemasyarakatan atau yang lebih tepat disebut perundang-undangan. Sebagaimana disebutkan dalam manuskrip tersebut, bahwa kitab Kuntara Raja Niti dan Jugul Muda adalah kitab perundang-undangan yang berlaku di tiga wilayah kerajaan besar, yaitu Majapahit, Pajajaran, dan Lampung. Sebagai naskah perundangundangan atau dasar hukum kehidupan bermasyarakat, kitab tersebut ditulis dengan sistematis. Setiap pembahasan diatur dalam bab-bab.

Bab I: Bab ini membahas tentang Kiyas. Kiyas adalah hal yang 
mesti pada hukum, yang menyangkut tiga persoalan yaitu 1. Kuntara, 2. Rajaniti, 3. Jugulmuda. Selanjutnya pada kitab tersebut diterangkan, di antara raja-raja yang memmiliki kewenangan tiga kebijakan itu adalah Prabu Satmata dari Majapabit, Raja Pakuan Sandikara dari Pajajaran dan Raja Angklangkara dari Lampung.

Bab II : memuat sejarah Raja Majapahit dan keagungannya. Dari bab ini bisa disimpulkan bahwa naskah ini sangat terpengaruh dengan kebesaran Kerajaan Majapahit.

Bab III: Bab ini menyebutkan penjelasan tiga pokok hukum di antara prinsip-prinsip hukum yang ada dalam Kuntara Rajaniti, yaitu Igama, Dirgama dan Karinah.

Igama adalah yang dihukumkan, berarti sesuatu yang nyata dan kasatmata, bisa diakui keberadaan dan kebenarannya oleh semua orang.

Dirgama itu hati nurani yaitu hukum-hukum yang ada pada kitab Kuntara Rajaniti sesuai dengan hati nurani. Karinah berkaitan dengan perbuatan yang dilakukan. Dengan ketentuan tiga pokok hukum ini, diterangkan bahwa hukum-hukum yang ada bisa diogolongkan; hukum yang bersifat nyata itu Kuntara, hukum yang sesuai dengan hati nurani disebut Rajaniti, sedangkan hukum yang berhubungan dengan sebab akibat suatu perbuatan disebut Jugulmuda.
Bab IV s/d VI: Bab ini membahas seputar kaidah bukum yang ada pada Bab III.

Bab VIII - XVII: Bab ini memuat produk hukum atau aturanaturan secara detail, yaitu:

Bab VIII: Bab ini menerangkan tentang bukum-bukum suami-istri.

Bab IX : Bab ini membahas tentang peraturan jual beli.

Bab X : Bab ini menerangkan tentang tanah.

Bab XI : Bab ini membahas tentang utang-piutang.

Bab XII : Bab ini membahas tentang gadai dan upah.

Bab XIII: Bab ini berisi tata cara bertamu dan menginap.

Bab XIV : Bab ini berisi tentang larangan mengungkit-ungkit persoalan.

Bab XV :Bab ini membicarakan tentang perjanjian.

Bab XVI: Bab ini mengatur tentang talak.

Bab XVII: Bab ini membahas tentang utang piutang.

Kitab perundang-undangan klasik

Kuntara Rajaniti dan Jugulmuda ini seandainya pemerintah kolonial Belanda tidak memaksakan berlakunya Wetboek van Strafrecht voor Nederlandsch Indie 1915 (Kitab Undang-Undang Pidana untuk Bangsa Jajahan Di Wilayah Jajahan 1915), diduga kuat naskah perundangundangan klasik Kuntara Rajaniti dan Jugulmuda niscaya masih berlaku sampai sekarang. Karena naskah Kuntara Rajaniti dan Jugulmuda dimaksud sudah lengkap memuat materi hukum pidana, perdata lalu-lintas angkutan secara komprehensif dan sistimatis dalam urutan Bab dan pasal-pasalnya.

Sehubungan dengan Pancasila sebagai sumber dari segala sumber hukum bagi negara dan bangsa Indonesia, maka jiwa dan rasa keadilan 
hukum bangsa Indonesia tersirat dalam nilai-nilai yang tercakup dalam setiap sila dari Pancasila itu sendiri tercakup juga dalam Kuntara Rajaniti dan Jugulmuda . Adapun sila-sila Pancasila itu adalah :

1. Ketuhanan Yang Maha Esa.

2. Kemanusiaan yang adil dan beradab.

3. Persatuan Indonesia.

4. Kerakyatan yang dipimpin oleh bikmah kebijaksaan dalam permusyawaratan dan perwakilan.

5. Keadilan sosial bagi seluruh rakyat Indonesia

Seluruh nilai dasar dari setiap sila dalam Pansila itu teruraikan dalam uraian Naskah Perundang-Undangan Klasik Kuntara Rajaniti Dan Jugulmuda. Untuk lebih memudahkan pengamatan bisa di lihat dalam klasifikasi nilai dalam tabel berikut:

\begin{tabular}{|c|c|c|}
\hline PANCASILA & $\begin{array}{c}\text { NILAI } \\
\text { SOSIAL }\end{array}$ & $\begin{array}{c}\text { KUNTARA } \\
\text { RAJANITI } \\
\text { JUGULMUDA }\end{array}$ \\
\hline $\begin{array}{l}\text { 1. Ketuhanan } \\
\text { Yang } \\
\text { Maha Esa }\end{array}$ & $\begin{array}{l}\text { Pengakuan } \\
\text { keyakinan } \\
\text { akan } \\
\text { Keberadaan } \\
\text { Tuhan. }\end{array}$ & $\begin{array}{l}\text { Punika sajarah } \\
\text { kanjeng } \\
\text { rasūlullāhi } \\
\text { shallallahu } \\
\text { ‘alaihi } \\
\text { wassallam.? }\end{array}$ \\
\hline $\begin{array}{l}\text { 2. Kemanusi } \\
\text { aan yang } \\
\text { adil dan } \\
\text { beradab }\end{array}$ & $\begin{array}{l}\text { Menebar } \\
\text { upaya kerja } \\
\text { dan do`a } \\
\text { selamat } \\
\text { sejahtera } \\
\text { antar } \\
\text { sesama. }\end{array}$ & $\begin{array}{l}\text { Diberlakukann } \\
\text { ya ketentuan } \\
\text { hukum tiga } \\
\text { perkarasebagai } \\
\text { perlindungan } \\
\text { sang Patih atas } \\
\text { rakyatnya dan } \\
\text { ketaatan rakyat } \\
\text { kepada Patih } \\
\text { dan Rajanya, }{ }^{10} \\
\text { yaitu hukum }\end{array}$ \\
\hline
\end{tabular}

9 Kuntara Rajaniti Dan Jugulmuda, h. 100; 102; 110

${ }^{10}$ Ibid, h. 104.

\begin{tabular}{|c|c|c|}
\hline & & $\begin{array}{l}\text { Igama, hukum } \\
\text { Dirgama dan } \\
\text { hukum } \\
\text { Karinah } 11 \\
\text { dengan } \\
\text { penjelasan dan } \\
\text { pengertiannya } \\
\text { masing- } \\
\text { masing'12. } \\
\text { Lamun ana } \\
\text { wong } \\
\text { anyerangnge } \\
\text { wong lagi } \\
\text { malaku } \\
\text { kalawan rabine } \\
\text { antara pitung } \\
\text { deppa arangnge } \\
\text { malaku lan } \\
\text { rabine ing } \\
\text { dadalan } \\
\text { mangka kedenda } \\
\text { tigang ngewu. } \\
\text { Lamun ratu } \\
\text { kang din } \\
\text { serangnge } \\
\text { salaksa } \\
\text { ingngaranan } \\
\text { Malaku Bava. }{ }^{13}\end{array}$ \\
\hline $\begin{array}{l}\text { 3. Persatuan } \\
\text { Indonesia. }\end{array}$ & $\begin{array}{l}\text { Mewujudka } \\
\text { n dan } \\
\text { memelihara } \\
\text { persatuan } \\
\text { dan } \\
\text { kesatuan } \\
\text { dengan } \\
\text { praktek } \\
\text { berbagi } \\
\text { kebersamaa } \\
\text { n }\end{array}$ & $\begin{array}{l}\text { Kewenangan } \\
\text { menjalankan } \\
\text { perintah tiga } \\
\text { perkara itu } \\
\text { dipegang ketiga } \\
\text { Ratu }{ }^{14} \text {, yaitu } \\
\text { Ratu Prabu } \\
\text { Satmata di } \\
\text { wilayah } \\
\text { Mojopahit, Ratu } \\
\text { Pakulun Sang } \\
\text { Dikara di } \\
\text { wilayah Pejajaran } \\
\text { dan Ratu } \\
\text { Angklangkara di } \\
\text { wilayah } \\
\text { Lampung }{ }^{-15} \text {. } \\
\text { Ketiganya di }\end{array}$ \\
\hline
\end{tabular}

\footnotetext{
11 Ibid, h. 110.

12 Ibid, h. 111.

${ }^{13}$ Ibid, h. 166-167.

14 Ibid, h. 112

15 Ibid, h. 109.
} 


\begin{tabular}{|c|c|c|}
\hline & & $\begin{array}{l}\text { bawah satu } \\
\text { kendali hukum, } \\
\text { Sang Mbah } \\
\text { Manasakti yang } \\
\text { disebut } \\
\text { Sangngaji } \\
\text { Saka }{ }^{16} \text {. }\end{array}$ \\
\hline $\begin{array}{l}\text { 4. Kerakyata } \\
\text { n yang } \\
\text { dipimpin } \\
\text { oleh } \\
\text { hikmah } \\
\text { kebijak- } \\
\text { saan dalam } \\
\text { permusya } \\
\text { waratan } \\
\text { dan } \\
\text { perwakilan } \\
\text {. }\end{array}$ & $\begin{array}{l}\text { Melaksanaka } \\
\mathrm{n} \text { hak dan } \\
\text { kewajiban } \\
\text { menggapai } \\
\text { kesempurna } \\
\text { an melalui } \\
\text { proses } \\
\text { prioritas } \\
\text { hikmah } \\
\text { kebijaksanaa } \\
\text { n. }\end{array}$ & $\begin{array}{l}\text { Adanya } \\
\text { ketentuan } \\
\text { hukum tigang } \\
\text { perkara. } \\
\text { Tegesi Tata iku } \\
\text { anggun-anggun } \\
\text { ning Ratu. } \\
\text { Tegesi Tata iku } \\
\text { wari sang Patih } \\
\text { maring kaum. } \\
\text { Tegesi Karama } \\
\text { iku } \\
\text { pangawulaning } \\
\text { kaum maring } \\
\text { sang } \\
\text { Patih, sang } \\
\text { Patih ngawula } \\
\text { maring Ratu. } \\
\text { Din kaya } \\
\text { mangkono } \\
\text { pangawulaning } \\
\text { kaum maring } \\
\text { Sang Patih } \\
\text { pacuan ora } \\
\text { nganggo tigang } \\
\text { perkara iku. }{ }^{17}\end{array}$ \\
\hline $\begin{array}{l}\text { 5. Keadilan } \\
\text { sosial bagi } \\
\text { seluruh } \\
\text { rakyat } \\
\text { Indonesia. }\end{array}$ & \begin{tabular}{|l|} 
Mewujudka \\
n harapan \\
kesejahteraa \\
n bersama \\
secara \\
merata \\
kepada \\
seluruh \\
individu, \\
kelompok \\
dan \\
golongan \\
bangsa. \\
Harapan \\
demikian \\
\end{tabular} & \begin{tabular}{|l} 
Lamun ana \\
wong lanang \\
mimisuh wong \\
wadon utawa \\
ana patani \\
utawa \\
kasersengngan \\
mangka \\
kadenda \\
kalihewu, kaya \\
mangkonon \\
wong wadon \\
amimisuh \\
wong lanang \\
malih mangka \\
\end{tabular} \\
\hline
\end{tabular}

16 Ibid, h. 113.

${ }^{17}$ Ibid, h. 103-105.

\begin{tabular}{|c|c|}
\hline $\begin{array}{l}\text { bisa tewujud } \\
\text { dengan } \\
\text { berlandaska } \\
\text { n kejujuran } \\
\text { totalitas, } \\
\text { yaitu jujur } \\
\text { secara lahir } \\
\text { dan batin } \\
\text { sebagaimana } \\
\text { sifat } \\
\text { kejujuran } \\
\text { yang } \\
\text { ditumbuhka } \\
\text { n dari } \\
\text { praktek } \\
\text { ibadah } \\
\text { puasa dalam } \\
\text { Islam. }\end{array}$ & 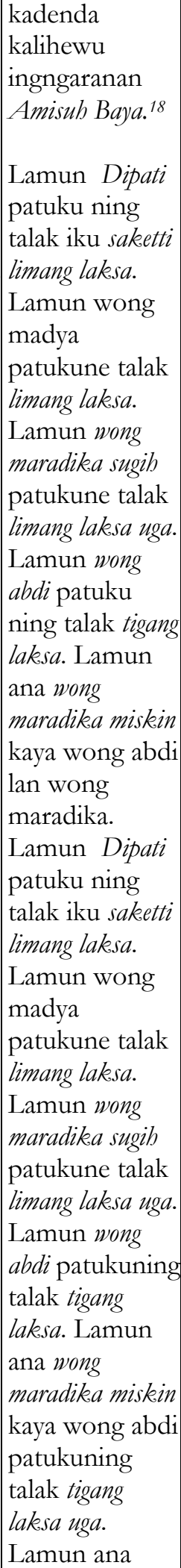 \\
\hline
\end{tabular}

18 Ibid, h. 155. 


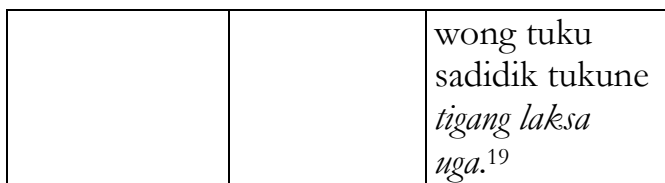

Dari uraian nilai setiap sila dari Pancasila ini terbukti seutuhnya tercakup dalam uaraian Naskah Perundang-Undangan Klasik Kuntara Rajaniti Dan Jugulmuda yang telah sempat lama berlaku di sebagian wilayah nusantara jauh sebelum diberlakukannya Perundang-Undangan kolonial belanda di nusantara.

\section{Penutup}

\section{Kesimpulan}

Berdasarkan data yang disajikan pada bab III laporan penelitian ini maka dapat disampaikan kesimpulan sebagai berikut:

a. Bahwa Pancasila merupakan Jiwa hukum dan rasa keadilan hukum bangsa Indonesia.

b. Bahwa nilai jiwa hukum dan rasa keadilan hukum bangsa Indonesia seutuhnya tersirat dalam PerundangUndangan klasik Kuntara Rajaniti Dan Jugulmuda.

\section{Saran dan Rekomendasi.}

Sehubungan dengan itu dengan ini disarankan agar pemerintah Negara Kesatua Republik Indonesia melestarikan dan mengakomodir nilai jiwa hukum dan rasa kedilan bangsa yang termuat dalam naskah perundangundangan Klasik Kuntara Rajaniti dan Jugulmuda.

\section{Daftar Pustaka}
B.Herry-Priyono, Guru-Guru keluburan, PT Kompas Media Nusantar, Jakarta, .2010.

Carl von Savigny, Von Beruf Unserer Zeit fur Gesetzigebung und Rechtswissenschaft
Naskah Kuntara Rajaniti Dan Jugulmuda
Petrus Citra Triwamwoto. Kewaryanegaraan. Grasindo, Jakarta, 2004.

Sucipto Raharjo, Ilmu Hukum, Pen. Alumni, Bandung 1982.

Wirjono Prodjodokoro, Azas-Azas Hukum Pidana Di Indonesia, P.T. Eresco, Bandung, 1979.

Zulyani Hidayah, Ensiklopedi Suku Bangsa di Indonesia, Yayasan Pustaka Obor Indonesia, Jakarta, 2015. 